\title{
CONTRIBUIÇÃO AO CONHECIMENTO DA GIANNETTITA DO COMPLEXO ALCALINO DE POÇOS DE CALDAS, MG*
}

\author{
H.D.Schorscher \\ M.M.G.Monteiro ${ }^{2}$ \\ A.Pérez Aguilar ${ }^{2}$ \\ G.M.Garda ${ }^{2}$ \\ F.Bohland $\mathrm{Neto}^{3}$ \\ B.Schulz-Dobrick ${ }^{4}$
}

A giannettita, um silicato de metais raros característico do complexo alcalino de Poços de Caldas, foi descrita como mineral novo por GUIMARÃES (1948, Inst.Tecnol.Industrial, Bol. 6 , Belo Horizonte), com base em dados microscópicos-petrográficos e mineralógicos-óticos fundamentais e químicos preliminares. Desde então vários autores contribuíram para o conhecimento deste mineral, novamente quanto às suas características óticas e petrográficas. A composição química, originalmente abordada por GUIMARÃES (op. cit.) e revista por BRANCO (1956, Inst.Pesq.Radioativas, Publ. n 5, Belo Horizonte), continua incompleta. A estrutura e os parâmetros cristalográficos são ainda desconhecidos, implicando no seu não reconhecimento por alguns autores como mineral definido.

Neste trabalho efetuamos estudos mineralógicos-petrográficos, de difração de raios $X$, bem como de química mineral por microssonda eletrônica, das giannettitas dos fonólitos subvulcânicos híbridos da Pedreira Bortolan e dos nefelina-sienitos miaskíticos da Pedreira da

\footnotetext{
*Apoio FAPESP.

${ }^{1}$ Departamento de Mineralogia e Petrologia, Instituto de Geociências, USP.

${ }^{2}$ Pós-graduação, Departamento de Mineralogia e Petrologia, Instituto de Geociências, USP.

${ }^{3}$ Graduação, Instituto de Geociências, USP.

${ }^{4}$ Miner.-Petrogr. Inst., Univ. Mainz
} 
Prefeitura, respectivamente localizadas a W e E da cidade de Poços de Caldas.

Os estudos petrográficos mostraram a cristalização pós-magmática, pneumatolitica a hidrotermal (catatermal) da giannettita, anterior apenas à aegirina fibrosa final e as zeólitas. Nas rochas subvulcânicas o hábito é extremamente poiquilitico/poiquiloblástico (com inclusões predominantes de nefelina, aegirina-augita e feldspatos alcalinos). Nos nefelina sienitos, apresenta hábito xenomórfico-intergranular, sendo raramente hipidiomórfico ou mesmo idiomórfico quando ocorre em micro-miarolos. Foi observada ainda a ocorrência quase que constante de zoneamento composicional e certa similaridade com a clinozoisita na aparência microscópica geral da giannettita.

Os trabalhos de separação mineral (bromofórmio, separação magnética e seleção final manual na lupa binocular) mostraram-se muito difíceis em função do tamanho pequeno $e$ do hábito do mineral. Ainda assim, obtivemos um cristal idiomórfico proveniente dos nefelina-sienitos da Pedreira da Prefeitura e poucos miligramas de concentrados de ambas as ocorrências, na fração granulométrica de 100-150 micra, de pureza variável. Os concentrados mais puros dos nefelinasienitos contém até $90 \%$ de giannettita, estimativa feita na lupa binocular. Os trabalhos de difração de raios $\mathrm{X}$, em andamento, incluíram métodos de monocristal e de pó.

Os estudos de química mineral, via microssonda eletrônica, foram efetuados com o equipamento automático Cameca/Camebax no Instituto de Mineralogia e Petrografia da Universidade de Mainz, República Federal da Alemanha. Incluíram testes qualitativos e análises quantitativas preliminares que mostraram a ausência dos elementos $\mathrm{Al}, \mathrm{Mg}, \mathrm{K}, \mathrm{Ba}$ e $\mathrm{Cl}$. Posteriormente, foram analisados quantitativamente 12 ou 15 elementos em mais de cem pontos de 30 cristais individuais de ambas as ocorrências. Nestas análises foram diferenciadas as bordas, partes intermediárias e os centros dos cristais para verificar o zoneamento composicional. Os resultados analficos mostraram boa homogeneidade composicional das giannettitas para cada ocorrência, individualmente considerada, com ressalva às variações inerentes ao zoneamento. Existem, porém, diferenças substanciais entre as duas ocorrências, destacando-se os teores consideravelmente mais elevados de $\mathrm{Sr}$, Mn e $\mathrm{F}$ e mais balxos de $\mathrm{Fe}, \mathrm{Nb}, \mathrm{Y}$, Ce e La nas giannettitas da pedreira Bortolan. Nota-se ainda que o fechamento das análises (totais corrigidos) se situa ao redor dos $96 \%$. A diferença de $4 \%$ é atribuída, em parte, à presença dos demais elementos terras raras e, possivelmente, à hidroxila. Ainda assim, poder-se-ia calcular com estes dados uma fórmula estrutural, admitindo-se analogia cristalográfica, por exemplo, com a hjortdahlita/guarinita, mineral do grupo da wöhlerita, conforme sugerido por FLEISCHER (1949, Amer.Miner., 34(9/10):770). Esta linha foi seguida por SOUBIÉS et al. (Rev.Bras.Geoc., no prelo) que, em trabalho independente sobre a mobilidade do zircônio, apresentaram algumas análises por microssonda eletrônica de giannettitas de outras ocorrências do complexo alcalino de Poços de 
Caldas, cujos resultados, apesar de não terem incluído todos os elementos por nós analisados, sâo compatíveis com os aqui apresentados, considerando a variabilidade regional deste mineral.

Apresentam-se a seguir um resumo dos dados da composição química por microssonda eletrônica das giannettitas dos nefelina-sienitos da Pedreira da Prefeitura de Poços de Caldas (NeS da PP) e dos fonolitos subvulcânicos da Pedreira Bortolan (F da PB), juntamente com a análise original de BRANCO (op.cit.)

\begin{tabular}{|c|c|c|c|c|c|c|}
\hline $\begin{array}{l}\text { Óxidos/ } \\
\text { elem. }\end{array}$ & \multicolumn{3}{|c|}{$\begin{array}{l}\text { NeS da PP } \\
\text { partes }\end{array}$} & \multicolumn{2}{|r|}{$F$ da PB } & $\begin{array}{c}\text { Branco } \\
\text { (1956) }\end{array}$ \\
\hline $\mathrm{SiO}_{2}$ & 30.18 & 30.04 & 30.04 & 30.09 & 29.96 & 38.17 \\
\hline $\mathrm{TlO}_{2}$ & 9.05 & 8.86 & 8.87 & 8.92 & 9.12 & 8.49 \\
\hline $\mathrm{Al}_{2} \overline{\mathrm{O}}_{3}$ & nd & nd & nd & nd & nd & - \\
\hline $\mathrm{FaO}$ & 0.82 & 0.81 & 0.74 & 0.79 & 0.36 & $2.20^{(*)}$ \\
\hline $\mathrm{MnO}$ & 0.85 & 0.72 & 0.67 & 0.75 & 1.65 & 9.42 \\
\hline $\mathrm{MgO}$ & nd & nd & nd & nd & nd & - \\
\hline $\mathrm{CaO}$ & 33.67 & 34.43 & 34.52 & 34.21 & 32.98 & 16.32 \\
\hline $\mathrm{Na}_{2} \mathrm{O}$ & 6.44 & 6.29 & 6.18 & 6.30 & 6.60 & 11.35 \\
\hline $\mathrm{K}_{2} \mathrm{O}$ & nd & nd & nd & nd & nd & - \\
\hline $\mathrm{BaO}$ & nd & nd & nd & nd & nd & - \\
\hline $\mathrm{SrO}$ & 0.52 & 0.41 & 0.40 & 0.44 & 2.02 & 2.30 \\
\hline $\mathrm{ZrO}_{2}$ & 3.50 & 3.54 & 3.26 & 3.43 & 3.45 & 8.39 \\
\hline $\mathrm{HFO}_{2}$ & 0.06 & 0.05 & 0.06 & 0.06 & 0.08 & - \\
\hline $\mathrm{Nb}_{2} \mathrm{O}_{5}$ & 1.09 & 1.00 & 0.94 & 1.01 & 0.76 & - \\
\hline $\mathrm{Ce}_{2} \mathrm{O}_{3}$ & 2.47 & 2.41 & 2.63 & 2.50 & 1.62 & - \\
\hline $\mathrm{La}_{2} \mathrm{O}_{3}$ & 1.43 & 1.34 & 1.38 & 1.38 & 0.94 & - \\
\hline $\mathrm{Y}_{2} \mathrm{O}_{3}$ & 0.88 & 0.95 & 1.00 & 0.94 & 0.49 & - \\
\hline $\mathrm{Cl}^{\circ}$ & nd & nd & nd & nd & nd & 3.90 \\
\hline$F$ & 9.42 & 9.13 & 9.10 & 9.22 & 10.38 & - \\
\hline total & 100.38 & 99.96 & 99.77 & 100.03 & 100.40 & - \\
\hline$F=0$ & 3.96 & 3.83 & 3.82 & 3.87 & 4.36 & - \\
\hline \multicolumn{7}{|l|}{ total } \\
\hline corr. & 96.42 & 96.13 & 95.95 & 96.16 & 96.04 & - \\
\hline \multicolumn{7}{|c|}{$\begin{array}{l}\text { bordas - composição média das bordas dos cristais } \\
\text { partes interm. - composição média das partes internas intermediárias dos cristais } \\
\text { centros - composição média dos centros dos cristais } \\
\text { todas - composição média de todos os pontos analisados } \\
\text { nd - não detectado } \\
\text { (*) - recalculado neste trabalho }\end{array}$} \\
\hline
\end{tabular}

